\title{
Emaranhados educacionais: a continuidade do viver e uma educação da atenção
}

\author{
Educational interweavings: the continuity of living and an education of attention \\ Enredos educativos: la continuidade de la vida y una educación del cuidado
}

Recebido: 15/10/2021 | Revisado: 24/10/2021 | Aceito: 25/10/2021 | Publicado: 28/10/2021

\author{
Alice Copetti Dalmaso \\ ORCID: https://orcid.org/0000-0002-4447-0958 \\ Universidade Federal de Santa Maria, Brasil \\ E-mail: alicedalmaso@gmail.com \\ Fernanda Monteiro Rigue \\ ORCID: https://orcid.org/0000-0003-2403-7513 \\ Universidade Federal de Uberlândia, Brasil \\ E-mail: fernanda_rigue@ hotmail.com
}

\begin{abstract}
Resumo
No presente estudo, produzimos uma escrita fiandográfica, a qual permite mobilizar a potência do pensamento do antropólogo Tim Ingold, referente à educação da atenção. Constituímos uma malha de pensamento-escrita que vincula educação como continuidade da vida, movimento dependente de uma composição relacional e atencional de comunhão e variação de saberes e experiências entre pares. Para tanto, é preciso reativar em nós uma experimentação aberta, atrelada a composições que demandem a presença de um corpo disposto a aprender a ser afetado, cuidadoso em suas dimensões relacionais, em frente às diferentes existências que compõem o universo educacional. Nesse sentido, instauramos convites: movimentar problematizações ao produzirmos espaços, práticas, tempos, discursos, estratégias, gestos menores, em Educação.
\end{abstract}

Palavras-chave: Fiandografia; Continuidade; Atenção; Educação.

\begin{abstract}
In the present study, we produced a thread-writed, which allows us to mobilize the potentiality of thought of the anthropologist Tim Ingold, referring to the education of attention. We constitute a mesh of thought-writing that binds education as continuity of life, a movement dependent on a relational and attentional composition of communion and variation of knowledge and experiences between peers. Therefore, it is necessary to reactivate us an open experimentation, linked to compositions that demand the presence of a body disposed to learn to be affected, thoughtful in its relational dimensions, forward of the different existences that arrange the educational universe. In this sense, we instituted invitations: to move problematizations to producing spaces, practices, times, discourses, strategies, minor gestures, in Education.
\end{abstract}

Keywords: Thread-writing; Continuity; Attencion; Educacion.

\section{Resumen}

En el presente estudio, producimos una escritura fiandográfica, que nos permite movilizar el poder del pensamiento del antropólogo Tim Ingold, respecto a la educación de la atención. Constituimos un tejido de pensamiento-escritura que vincula la educación como la continuidad de la vida, un movimiento dependiente de una composición relacional y atencional de comunión y variación de conocimientos y experiencias entre pares. Por tanto, es necesario reactivar en nosotros una experimentación abierta, ligada a composiciones que exigen la presencia de un cuerpo dispuesto a aprender a ser afectado, cuidadoso en sus dimensiones relacionales, frente a las distintas existencias que componen el universo educativo. En este sentido, introducimos invitaciones: mover problematizaciones produciendo espacios, prácticas, tiempos, discursos, estrategias, gestos menores en Educación.

Palabras clave: Fiandografía; Continuidad; Atención; Educación.

\section{Introdução}

Quem é mais sábio: o ornitólogo ou o poeta - quem sabe o nome de cada pássaro, mas já os têm pré-classificados na mente; ou quem não conhece nenhum nome, mas olha encantado, admirado e perplexo para tudo o que vê? (Ingold, 2015b, p. 22-23). 
Exposição ao mundo, expondo-se a si mesmas em testemunhar o que se vê, sente, ouve. Acompanhar e esperar por um campo de possibilidades que nasce continuamente diante de nossa percepção: encontrar a atenção que se aviva para essa emergência, para então produzir novos começos: eis o que pode ser um chamado em educação.

O antropólogo Tim Ingold nos convida a pensar uma educação que engendra configurações perceptivas de um poeta, na qualidade sensível de uma atenção que se abre ao que está disponível no mundo, abandonando a pretensão de saber mais, conhecer mais, cognitivamente. Aprender, neste sentido, será equivalente a uma educação, que não corresponde a um hostil enchimento/acúmulo de conhecimento em alguém, mas do desenvolvimento de uma habilidade, uma afinação perceptiva do mundo. Essa linha de pensamento nos incita a pensar a educação como um espaço relacional-atencional, capaz de nos tornar hábeis em responder ao que acontece com cuidado e sensibilidade, expondo nosso corpo a aprender a ser afetado pelo mundo.

O objetivo deste manuscrito é fazer variar as contaminações suscitadas a partir dos estudos do autor supracitado, o qual torce uma relação com a atenção e o campo antropológico para defini-la, ela mesma, como educação. Não são meras interfaces entre antropologia e educação, mas a própria defesa da correspondência de princípios entre ambas que Ingold se debruça (Ingold, 2020).

O antropólogo experimental afirma que só podemos conhecer o mundo, movendo-nos. Movendo-nos é que aprendemos a descrever o que se apresenta no mundo. Mover, conhecer e descrever, no entanto, demandam observação (e observar é perceber o que se passa no acontecimento). Um ser que se move, conhece e descreve, deve estar atento e "[...] estar atento significa estar vivo para o mundo" (Ingold, 2015a, p.13).

Ressalta-se esta frase: estar atento significa estar vivo para o mundo (ou seja, não é meramente no mundo, passivamente, mas, estar atento na sua forma mais ativa e viva). Este para denota certa abertura, disposição, de encontrar o mundo, num estado virtual, com seres e coisas sujeitas a serem descobertas, conhecidas e sentidas. Esse conceito nos convoca a uma configuração - um jeito novo de existir, ativação mínima do nosso sistema corporal, perceptivo, sensível - de ser capaz de atentar para mundo, uma atenção que "[...] acompanha um mundo que não está pronto, que é sempre incipiente, que se encontra no limiar da emergência contínua" (Ingold, 2015b, p. 29). Esse mundo, então, pode se tornar uma fonte de espanto, de inusitado, como uma criança que, aprendendo a se movimentar, na crista de um nascimento para o mundo, interrompe o seu percurso para olhar, pegar, cheirar, explorar o que a chama, o que a convida a parar, no percurso do seu caminho.

Entrar em contato com esse campo conceitual de Tim Ingold convoca a entrar numa relação de aprendizado da atenção, o qual equivale a afinar um sistema perceptivo em educação, pensando os atravessamentos dessa qualidade corporalperceptiva nas nossas relações humanas e não-humanas, nos diferentes espaços e com os diferentes sujeitos com os quais nos encontramos.

Educação, portanto, não é uma palavra ou conceito cuja direção se possa indicar como boa, ou desejável por quem participe de uma ação caracterizada como educacional. Nesse ponto é preciso encarar que há processos educacionais incríveis nas relações de uma mãe com seu filho de colo, de uma criança descobrindo o mundo, de um velho aprendendo a não ressentir. Há, também, incríveis processos educacionais no narcotráfico, nas guerras, em um jovem que inibe sua força sexual em função do modo como se entende percebido seu grupo social. Defendemos que educação é uma palavra carregada de sentidos relativos a infinitas práticas. E aí, uma palavra que, sem boas precisões, se torna inútil (Corrêa, 2014, p. 2-3).

Em decorrência disso, nos propomos aqui a fazer variar a condução de perspectivas novas a partir das ressonâncias Ingoldianas, evocando outras vozes, as quais se emaranham à percepções que vamos produzindo enquanto educadoras, ensejando um tom menor (Ingold, 2020) aos nossos gestos em educação, num movimento ressonante de promover o convite a nós mesmas: de angariar uma atenção como uma maneira de estar junto, entre crianças, adultos, velhos, no cenário sabidamente multifacetado pelos quais produzimos a educação no território brasileiro. 


\section{Metodologia}

Este estudo se modula dentro de uma perspectiva de pesquisa e escrita fiandográfica. Uma Fiandografia (Dalmaso, 2016) atenta às linhas de que somos feitos, as linhas que dizem de uma vida, tornando-a linhas de escrita. Fiandar recorre a uma operação-ação-postura-movimento que se faz através dos próprios processos de ler-escrever-bordar e do que se aprende em contato com as tessituras ainda não-pensadas e sentidas em meio a esses gestos. Implica em processos de experimentação e pensamento que desconfiguram e amontoam ideias, desvinculando-se de certa normatividade de escrita e de pesquisa acadêmica, de consensos entre autores/as, de verdades sobre educação.

Nesse sentido, consideram-se sempre os desejos de ser atravessada pelos nós que podem ser entre heterogêneos, produzindo locuções com investimentos (e desinvestimentos) de si, na desmontagem e agenciamentos com muitas linguagens, variantes, obtusas, silenciosas, dissensuais. Trata-se de um processo de arregimentar, inventar espaços de escritas e composições com matérias-textos-seres que estiverem ao alcance, produzindo possibilidades de vida e pensamento com elas. Um empreendimento metodológico, afinal, que visa responder a um forte empreendimento vital: mais criar (criar com), do que sermos criadas em educação e na vida.

Trata-se de uma permissão autoral de uma escrita-pensamento que opera por diferenças inesperadas, através do envolvimento com nossa potência articulatória com vozes múltiplas, de diferentes campos de saber, compondo uma malha de linhas que se entrelaçam, de composições de pensamentos e signos poéticos. Opera-se, assim, o que entendemos como prática: “[...] consideramos a realidade, o pensamento, o conhecimento (a também a ação) enquanto eles estão se produzindo (grifo do autor)" (Lapoujade, 2017, p. 11). Nesse sentido, o leitor encontrará interferências e afetações recíprocas, a fim de posicionar o manuscrito como campo de paisagem desordenadamente visionária, não-representativa, do que podemos encontrar ainda de não pensado-sentido em educação (e, propriamente, enquanto gesto de pensar-escrever). Novamente, trata-se de convites, chamados, evocações inaudíveis às quais o leitor pode enlaçar seus dedos para nos acompanhar nessa malha, se assim puder e quiser.

\section{Da Continuidade: Comunhão e Variação}

Não os ensine a serrar se você não souber segurar uma serra; não os ensine a cantar se você achar chato cantar; não se disponha a ensiná-los a viver se você não amar a vida (Deligny, 2020, p. 41).

Em seu livro Antropologia e-como educação, Ingold (2020) procura ruir a noção pedagógico-tradicional-ocidentalcolonizadora de educação como um processo de transmissão intergeracional de conhecimento autorizado: educação não se configura, assim, em inculcar nada a ninguém, mas liberar, abrir caminhos de crescimento e descobertas sem finais de chegada, pontos fixos. "Trata-se de dedicar atenção às coisas, em vez de adquirir conhecimento que nos absolva da necessidade de fazêlo (...) [educação] (...) é sobre exposição em vez de imunização" (Ingold, 2020, p. 10).

Nosso interesse em olhar para as contribuições de um antropólogo - que arrisca definir como ele deseja construir sua noção de educação - está imbricado a uma atmosfera acontecimental de atentar para a vida que se faz com o mundo, da educação como uma prática de atenção e não de transmissão. Ademais, concebe a educação como uma maneira, um jeito, uma configuração perceptivo-corporal de conduzir a vida. A diferença entre conduzir a vida e viver é a própria prática de atenção. “"Atenção' vem de ad-tendere, que significa 'alongar (tendere) em direção a (ad). É o alongamento da vida que busco" (Ingold, 2020, p. 38).

Estender a vida: uma educação como prolongamento, alongamento, continuidade da vida pode ser encontrada em longas passagens dos escritos de Ingold (2020). A educação, como uma prática de atenção e não de transmissão - é onde se 
dará a geração e continuação do conhecimento, alongamento temporal da vida. No entanto, esse processo de continuidade nunca é individual, mas social e coletivo, comunitário: educação, então, será esse meio onde o processo de continuidade social da vida ocorre - "Onde e quando a vida estiver acontecendo, assim também está a educação" (Ingold, 2020, p. 18).

Porém, encontrar os meios de continuidade da vida é permitido, afinal, por um processo de comunicação. De fato, em função dos vícios representacionais-computacionais do verbo comunicar, Ingold prefere utilizar o verbo comungar, próprio da vida social: uma maneira compartilhada de fazer e organizar a vida com participantes implicados juntos nos processos de estar vivo no aqui e agora. "Nos contextos da educação, esta comunhão é acima de tudo realizada por pessoas de diferentes gerações" (Ingold, 2020, p. 19). Porém, a suposta informação não é concebida como algo que se passa, transmite, de uma cabeça que tem mais para uma que tem menos. Como escreve Ingold (2020, p.19), para que esse compartilhar "[...] seja educativo, eu tenho que fazer um esforço imaginativo para lançar minha experiência de maneira que ela possa se juntar à sua, para que possamos - em certo sentido - percorrer os mesmos caminhos e, ao fazê-lo, criar sentido juntos".

Nossa intenção aqui é perceber que ainda que ocorram usos dos termos transmissão e comunicação - usualmente utilizadas dentro de uma pedagogia formal - eles se apresentam para compor o saber de que essa comunicação é da ordem de comungar uma experiência intergeracional,

[...] através da participação recíproca na vida de cada um - através dos esforços contínuos e implacáveis de jovens e velhos, imaturos e maduros, para chegar a uma espécie de concordância - que a educação e os conhecimentos, valores, crenças e práticas de uma sociedade são perpetuados (Ingold, 2020, p. 19-20).

Há aí um misto entre imitação e improvisação que ocorre como prática atencional - educativa - para Ingold. Toda ordem comunicativa-comungada que aqui se fala é codependente do ambiente que se vive e da variação-criação daquilo que se mostra, daquilo que se faz, se vê, se sente e se pensa. Criação contínua, como afirma Ingold (2020), enquanto descoberta, variação do que cada participante traz.

O que assegura o processo educativo é que haja um compactuar de riscos entre gerações, do contrário, Ingold afirma que estaríamos falando apenas de treinamento, e não de educação. Essa variação nos assegura a não cairmos (sermos enfeitiçados) por uma noção naturalizada no campo da escolarização como garantia de transmissão dos conhecimentos, a saber: a de pessoas com menor saber e maior saber; menor propriedade e maior propriedade; de imaturidade como falta ou vazio; de uma identidade primordial e melhorada.

Na passagem das gerações humanas, a contribuição de cada uma para a cognoscibilidade da seguinte não se dá pela entrega de um corpo de informação desincorporada e contexto-independente, mas pela criação, através de suas atividades, de contextos ambientais dentro dos quais as sucessoras desenvolvem suas próprias habilidades incorporadas de percepção e ação. Em vez de ter suas capacidades evolutivas recheadas de estruturas que representam aspectos do mundo, os seres humanos emergem como um centro de atenção e agência cujos processos ressoam com os de seu ambiente. O conhecer, então, não reside nas relações entre estruturas no mundo e estruturas na mente, mas é imanente à vida e consciência do conhecedor, pois desabrocha dentro do campo de prática - a taskscape- estabelecido através de sua presença enquanto ser-no-mundo. A cognição, neste sentido, é um processo em tempo real (Ingold, 2010, p. 21).

A emergência de um processo entre o que nomeamos como corpo e mente se faz em comungar da vida das pessoas no mundo, numa criação contínua com o ambiente. Há, portanto, um acoplamento, de fluxos heterogêneos que se encontram, entre o que chamamos de indivíduo e meio. Dessa maneira, serão modos de vida a serem compartilhados e expandidos, como afirma Coccia (2020) - metamorfoseados, não conteúdos a serem transmitidos.

Em contrapartida, sabemos que, para projetos de pedagogia universal - de homem, de ciência e de sociedade - anulase o que de singular se faz numa criança ou num grupo de crianças, por exemplo - dinamitando a dinamicidade e abertura das 
mesmas para o mundo, anulando toda ordem inventiva de um corpo e mente que vazam corporalmente pelo mundo, abertas ao que chega em conjunto com seus pares. Estaríamos embrutecidos da vida comum - de comunidade - se fossemos sempre reduzidos a graus de saber maiores e menores, ou à suposta homogeneidade nos graus de transferência de informação, erradicando todo processo de comungar e produzir diferença social coletiva. Porém, essa é a linguagem da pedagogia standard: “[...] equivalente a um método de transmissão, julgado em termos de sua eficiência não em crescimento de pessoas ou de seus conhecimentos, mas na transcrição de conteúdo preexistente de cabeça a cabeça" (Ingold, 2020, p. 37).

Assim, é junto de Ingold que desejamos elucidar uma educação da atenção onde se segue os outros e, simultaneamente, em comunhão, talha-se o caráter de que todos têm algo a ser oferecido, exatamente por não haver nada em comum. Assim, generosamente, gerações podem coexistir, habitar no mundo aberto “[...] em virtude de sua imersão comum nos fluxos do meio" (Ingold, 2015a, p. 179) - uma aspiração que exigirá amplo esforço dessa comunidade.

A variação (não semelhança) entre os seres e a comunhão formam, proliferam e mantém uma comunidade educacional, a "[...] continuidade da vida-em-um-ambiente" (Ingold, 2020, p. 22). Ou seja, ainda que a palavra atenção evoque uma série de significados usuais, como cuidar de pessoas, esperar, estar presente ou entrar em presença, acompanhando outros e coisas, Ingold (2020) expõe um "[...] significado adicional para o alongamento da vida - um temporal - pelo qual, com bios, a vida não é meramente vivida no aqui e agora, mas é esticada por uma memória de futuro que se permite que cada momento presente possa ser um novo começo" (p. 39): uma espécie de redescobrimento dirigido. O alongamento de uma vida gesta, assim, uma memória de futuro.

Nesse sentido, as ações que empreendemos no mundo - as coisas que fazemos - assumem e extraem alguns dos seus significados das coisas pelas quais passamos no curso de feitos anteriores, ou pelas quais passamos sob condições ambientais que essas ações causaram. E, por outro lado, o que atualmente enfrentamos na realização dessas ações, e as consequências ambientais que elas trazem a seu turno, se sustentam em seus fazeres posteriores (Ingold, 2020, p. 39).

Isso é conceber a continuidade do viver, ou podemos dizer, uma continuidade da própria transformação. Isso é promovido pela conexão disruptiva entre fazer (envolvendo uma ação, uma atividade) e um passar por (ser atravessado, afetado pelo ambiente). Por sua vez, gera um hábito, que segundo Ingold, consiste ele mesmo num princípio de produção "[...] em que um eu que habita em suas próprias práticas é recursivamente gerado por elas. Como tal, o hábito é o que o passar pelas coisas traz para a tarefa do fazer" (Ingold, 2020, p. 40). É isso que gera a noção de continuidade, pela qual consiste um processo de agir sobre o ambiente e de ser afetado pelo mesmo.

\section{Do Hábito: Fazer e Passar por Algo}

O conceito de hábito de Ingold foge ao significado usual com que costumamos utilizar essa palavra: de um modo fixo, dado e estabelecio de viver e fazer as coisas, cumprir tarefas. Ao contrário, vemos que esse hábito não é nem produtor e nem produto, mas “[...] o próprio princípio de produção, em que um eu que habita em suas próprias práticas é recursivamente gerado por elas" (Ingold, 2020, p. 40). Por intermédio do fazer, que está dentro do passar por algo, é que nós habitamos o mundo.

Será, então, na experiência de habitar produzida por Ingold que consistirá um processo de atenção: o fazer está dentro de passar por algo, cair dentro da própria corrente da ação. "Em meio a essa produção, ao mesmo tempo do eu e do mundo, o 'eu' está continuamente em questão" (Ingold, 2020, p. 43), abrindo vias de um hábito afirmado enquanto modo de mostrar que nunca se "[...] é totalmente mestre dos próprios atos; que conduzir a vida não é necessariamente estar no comando" (Ingold, 2020, p. 43). O eu, que rege a agência prévia dos atos, já não se põe à frente da ação, mas se forma e transforma de dentro da 
própria ação. Podemos, assim, reger-se em verbo: compor-se com, agenciar-se a, tornando-se algo nesse agenciar, na assembleia que se faz com o mundo (ou fazer passando por) (Ingold, 2020).

Em muitos de seus escritos, Ingold escolhe o gesto do caminhar como ilustração de uma atenção enquanto hábito, diferente da intenção. Quando o caminhar envolve um movimento intencionado, acaba por solicitar demasiadamente de nós uma atenção focalizada e focalizante que faz com que a mente cheque o mundo a todo instante, interrompa o movimento, contornando potenciais riscos do caminhar, controlando os acontecimentos. Quando a atenção, no entanto, corresponde ao princípio do hábito (fazer e passar por), produz um caminhar em que o pedestre responde, sim, continuamente ao terreno, ao caminho e aos elementos que surgem, mas na medida em que se caminha, experimenta o caminhar: "Para responder, ele deve atentar a essas coisas enquanto caminha, participando ou participando com elas em seus próprios movimentos. É isso que significa ouvir, observar e sentir" (Ingold, 2020, p. 45). Nesse sentido, segundo Ingold, no relato da caminhada por intenção, temos uma atenção que "[...] interrompe ou corta o movimento de modo a estabelecer uma relação transversal entre mente e mundo (cuja separação é assumida desde o início)" (Ingold, 2020, p. 45); ao contrário da atenção por hábito, onde o pedestre ajusta seu movimento ao terreno à medida que ele surge e se desdobra sob seus pés, convida uma atenção corporificada, encarnada, juntando-se ao que surge no acontecimento, conhecendo as coisas enquanto elas nascem e surgem no percurso da experiência presente, que se faz presença, extensão.

Caminhar deixa de ser algo que eu determino meu corpo a fazer, como uma rotina autoimposta. Em vez disso, parece que eu me torno o meu caminhar, e que a minha caminhada me leva. Eu estou lá, dentro dela, animado pelo seu movimento. E a cada passo eu não sou tão mudado quanto modificado, não no sentido de transição de um estado para outro, mas de renovação perpétua. Eu serei de fato uma pessoa diferente quando chegar; não a mesma pessoa em outro lugar, ou com um corpo marcado pelos estigmas de passagem. Até as dores e os calos se desdobram ativamente em minha experiência como parte de uma vida pela qual passo ativamente, e pode ser ainda mais dolorosa porque: goste ou não, eu não posso separá-las do ser andante que sou (Ingold, 2020, p. 42).

Ingold não deseja negar a existência de uma mente que está em ação na atenção de andar, assim como está na intencionalidade de dar um passeio. "Mas isso não é uma mente confinada à cabeça e colocada contra o mundo; é, na verdade, uma mente que se estende ao longo dos percursos sensoriais da participação do pedestre no ambiente" (Ingold, 2020, p. 46). Eis aí o alongamento da vida no princípio do hábito: a consciência de uma mente que se estende ao longo do que surge, caindo na corrente da ação, participando do mundo; uma mente do ser-com, não tomando as coisas como objeto (em oposição dualista a um 'eu'), mas como companheiras ou cúmplices, passando a conduzir a vida que the tira do seu comando automatizado frente às coisas e seres. É como uma experiência de estar dentro de um fluxo comunitário, “[...] como um nexo de vida e crescimento dentro de uma malha de relações, o organismo não é limitado pela pele. Ele, também, vaza" (Ingold, 2015a, p. 141). Tal qual escreve Ailton Krenak (2020), um microcosmos do organismo Terra conectado pela via da vida, do ar que respiramos, de uma fruição que estabelecemos com o mundo, com a malha “[...] uma dança, só que é uma dança cósmica” (p. 108).

Como fazer circular essa atenção nos nossos entendimentos e gestos usuais educacionais? Como criar situações a quem se mostra um modo de caminhar pelo hábito?

Seja caminhando por uma trilha ou copiando um texto, o pedestre ou escriba se submete a uma linha que sempre o tira de posição. Não tendo uma meta, um fim em vista, sempre esperando, sempre presente, exposto e não obstante impressionado pelo mundo através do qual ele vaga, ele não tem nada a aprender nem nada a ensinar. Seu itinerário é um modo de vida, mas é um modo sem conteúdo a transmitir. Não há corpo de conhecimento a ser passado adiante. E porque não há nada a ser passado adiante, não há métodos para fazê-lo (Ingold, 2015b, p. 33). 
Sabedoria da experiência. Encontramos aqui a noção de uma qualidade atencional que se constrói a partir de uma cognição encarnada, algo que se cria nos contextos de cada socius. Essa cognição que desabrocha no campo da prática é elaborada no nível de certa consciência de sua presença física e perceptiva naquilo que faz, enquanto algo que se dá entre mundo, corpo e mente (um continuиm entre essas instâncias e forças). Assim, esse conhecer traz a tônica os gestos, como os de ouvir ou olhar, por exemplo, que acompanham um outro ser, seguindo-o, que se sabe atento - aberto, presente - na ação. Para Ingold, essa seria uma educação da atenção, a qual envolve um processo de aprendizagem.

Mas para fazê-lo, sua ação deve estar acoplada de modo próximo e retido com sua percepção - ou seja, um monitoramento sempre vigilante do caminho, à medida que ele vai se desdobrando. Colocado de forma simples, você tem que prestar atenção onde pisa, e também ouvir e sentir. (Ingold, 2015b, p. 02).

Do corpo à mente imanente: uma percepção aterrada no real, nos fluxos, nos contornos, intensidades e ressonâncias (Ingold, 2010) restaurando um lugar dos sentidos do corpo: "Pois é, certamente, através dos nossos pés, em contato com chão (embora mediados pelo calçado), que estamos mais fundamental e continuamente 'em contato' com o nosso entorno" (Ingold, 2015a, p. 87).

Essa concepção do antropólogo Ingold se costura, como malha ${ }^{1}$, aos pensamentos de Krenak (2020), quando alerta que nosso rastro no mundo tem sido a ampliação da capacidade de 'comer o próprio mundo', desmatá-lo, explorá-lo, a ponto de estarmos investindo massivamente em construir tecnologias cada vez mais eficazes na busca desenfreada por encontrar outros mundos, os quais nos permitam habitar nele. Pensamos que escolarização, enquanto construção humana, está ancorada no investimento permanente da produção de uma vida útil, interessante aos desígnios de uma prospecção de futuro que retroalimenta o sucesso como aquisição e consumo de bens e produtos inerentes à capitalização da vida, do giro de uma economia, e...e...e... São modus operandis que capturam em nós, seres do/no mundo, a potência para viver ao nosso modo, nos fazendo colapsar numa insistência produtivista que nos reduz à uma fábrica de produzir respostas, verdades, duplos códigos e informações que estão interessadas em respaldar a vida utilitária e utilitarista, essa mesma produzida pelo homem civilizado que também captura e 'come/consome o mundo', devorando algo por onde passa, inclusive nossas subjetividades, as quais personificam a mesma coreografia, "[...] um pisar duro sobre a terra" (Krenak, 2020, p. 114). Um rastro compulsório e civilizatório que potencializa a orientação para o extermínio de um "[...] contato com a experiência de estar vivos para além dos aparatos tecnológicos que podemos inventar" (Krenak, 2020, p. 11-12), uma ideia de vida humanizada descolada da terra.

Essas relações de forças que atingem nossas instâncias de organização e atuação escolar, apostam no contínuo desenvolvimento cognitivo e metanarrativo sem que isso tenha necessariamente consigo a dimensão ética e acontecimental (do envolvimento ativo da experimentação com o mundo, da caminhada leve na terra, da capacidade permanente de estarmos recriando mundos o tempo inteiro (Krenak, 2020).

Em se tratando da docência, persistimos investindo, na maioria das vezes, nessa premissa pela qual fomos 'educadas/os'. Ora, quando nos percebendo desenvolvendo algum trabalho educativo (com crianças, jovens ou adultos), pomos em movimento um caminhar para a mente - já que é nela, na cognição, que percebemos se debruçar boa parte dos conhecimentos que compõem o rol escolar (Dalmaso; Rigue, 2020, p. 35).

Nas agruras de uma supervalorização de uma mente desincorporada no campo da formação - portanto, de uma desatenção vivida e produzida - como ativar esse hábito-atenção que pede uma presença? Como uma mente imanente ao

\footnotetext{
${ }^{1}$ A noção de malha emerge de Ingold (2015a) para pensar as interações - "Organismos e pessoas, então, não são tanto nós em uma rede quanto nós em um tecido de nós, cujos fios constitutivos, conforme se amarram a outros fios, em outros nós, compreendem a malha" (p. 120). A malha, portanto, são "[...] linhas emaranhadas de vida, crescimento e movimento" (p. 111), interações de forças que criam vida, modulam existências.
} 
movimento pode dar a ver, pensar e viver outros processos e estratégias educacionais? Encontrar esse modo de caminhar, de se mover por entre situações e paisagens, solicita abrir frestas quanto ao aprendizado de acompanhar a emergência daquilo que surge no processo, de um aparecer de coisas, pessoas, seres, existências que emergem como novidade quando testemunhamos sua própria emergência (Krenak, 2020), seu próprio nascimento contínuo, variável e coletivo (Coccia, 2020) - um envolvimento que pede passagem.

"Se ficarmos presos a uma concepção de mundo chapada, de mercadorias, de controle e dominação, é claro que vamos morrer de medo, mas experimente sair de dentro desse carro, experimente ter uma relação cósmica com o mundo" (Krenak, 2020, p. 71). Talvez aí se trate de renunciar ao que supostamente conhecemos e naturalizamos na humanização incessante dos processos educacionais, das nossas certezas escolarizadas carregadas e suportadas por onde vamos, para perceber o que nasce de novo num mundo atencional, presente e vivo que se funda na experiência imediata de viver os movimentos, os processos, que se abrem ao que não se sabe, que está aquém do conhecimento a priori, porque as coisas começam, então, a vazar, a nascer.

\section{Do Corpo: Aprender a Ser Afetado, Cuidados e Presenças}

Esteja presente, sobretudo quando não está ali (Deligny, 2020, p. 37).

O convite o qual Ingold nos arrasta é de pensar uma educação que se expõe ao mundo pelo comungar desse hábito, atraindo-nos para o próprio movimento de atender a ele numa estrada " [...] ao longo da qual o mundo se abre e se faz presente para nós, para que nós possamos estar expostos a esta presença e sermos transformados” (Ingold, 2020, p. 51-52).

Residirão aí relações imbricadas de entradas, atendendo às coisas e seres do mundo, esperando e aceitando-as, sobretudo seguindo com o que elas são e fazem; e um lado de saída, onde o mundo nos espera, onde detecta-se as possibilidades e oportunidades para seguir, escolhendo e se voltando para características propícias de um mundo que já está definido (Ingold, 2020).

Essas paragens, mais do que esmiuçar o atravessamento conceitual do autor, servem-nos para conjugar com o que consideramos uma postura-corpo atencional que desejamos aqui insuflar em nossas concepções educacionais, não para encontrar supostas respostas ao que entendemos por insuficiências pedagógicas, mas para, sobretudo, inventar palavras, imaginar mundos, angariar tons menores ${ }^{2}$ no demasiadamente mortificado em educação, a partir de novos sentidos intensivos produzidos nesse território. Inéditos comprometidos com o chamado para novas circunstâncias, como escreve Deligny (2018), com a criação de circunstâncias intensivamente libertárias.

Entendemos que para atravessarmos a noção da prática de atenção como educação, sobremaneira temos de passar pelo corpo, um corpo que, aquém de definições em seus termos fisiológicos-fenomenológicos, precisa ser articulado, animado, afectado 3 pelo, com e no mundo, já que se está vivo, ativo, em fluxo. A noção de corpo afetado não é explorado por Ingold e tampouco corrobora com os muitos escritos de outro antropólogo o qual traremos aqui, que é Bruno Latour. Por isso, é importante frisar que não desejamos unir autores que não compactuam dos muitos de seus com prismas teóricos e conceituais.

\footnotetext{
2 “Assim, poderíamos falar de uma educação que leva para fora, através de exposição em vez de doutrinação, que é conduzida em tom menor. A analogia musical é apropriada, pois a diferença entre os modos maior e menor é justamente de que enquanto o maior é confiante, assertivo e afirmativo, o menor é ansioso, inquieto e inquisitivo. [...] apenas uma educação em tom menor pode proporcionar uma liberdade que é real em vez de ilusória e que nos leve para fora de estruturas de autoridade que são manifestamente insustentáveis" (Ingold, 2020, p. 59).

${ }^{3}$ Afecção "[...] remete a um estado do corpo afetado e implica a presença do corpo afetante, ao passo que o afeto remete à transição de um estado a outro, tendo em conta variação correlativa dos corpos afetantes" (Deleuze, 2002, p. 56).
} 
Apostamos, porém, na experimentação, na imbricação rizomática de seus atravessamentos, compondo realizações imperfeitas, gritos disruptivos, afetos dissonantes entre eles, a fim de explorar nuances e combinações novas entre disciplinas, autores e fronteiras. Assim, como fizemos com os pensamentos de Krenak (2019; 2020), Deligny (2018; 2020) e Coccia (2020) convocamos os escritos de Bruno Latour neste momento do manuscrito, o qual expõe uma relação corporal com o mundo (Quantos corpos podemos ter?). Extraímos excertos de seus escritos a fim de transversalizar com as demais linhas lançadas até aqui.

Bruno Latour afirma que “[...] ter um corpo é aprender a ser afectado, ou seja, 'efetuado', movido, posto em movimento por outras entidades, humanas ou não-humanas. Quem não se envolve nesta aprendizagem fica insensível, mudo, morto" (Latour, 2008, p. 39). Um corpo que, longe de ser definido por categorias científicas ou metafísicas, abre-se para ser em si mesmo uma trajetória dinâmica, aprendendo a ser sensível "[...] àquilo de que é feito o mundo" (Latour, 2008, p. 39). Toda ambiguidade, variação, vivacidade se tornará atenção se esse corpo for assim mesmo exposto como "[...] um interface que vai ficando mais descritível quando aprende a ser afectado por muitos mais elementos" (Latour, 2008, p. 39).

Aprender a ser afetado não implica conduzir/cooptar/conscientizar/tirar alguém da desatenção para a atenção, ou de uma semiconsciência para a apreciação consciente, como afirma Latour. Ensinar-se a si mesmo a ser afetado, efectuado, por algo ou alguém, conjuntamente, é ir adquirindo um corpo progressivamente-temporalmente, que além de ser um meio sensorial, nasce faz nascer (Coccia, 2020) e, como diz Krenak (2020), recupera um mundo sensível.

Produzir, arregimentar, agenciar, não um corpo competente e autossuficiente, mas um corpo animado, que está sempre no meio do 'fazer passando', aberto aos riscos, inseguranças, desvios de caminhos, ao estranhamento de base insegura: uma complexidade infinita que nos solicita uma atenção lenta, mas que responde ao mundo fenomenal. "Concentrando-nos no corpo, somos imediatamente - ou antes, mediatamente - conduzidos àquilo de que o corpo se tornou consciente" (Latour, 2008, p. 39).

Para não dualizarmos mais ainda a relação já tão perpetuada entre mente e corpo, criança e adulto, professor e aluno, sujeito e objeto, é preciso que encaremos as camadas simultâneas de variáveis que podem sensibilizar ou não um corpo para as diferenças existentes no mundo. Independente das formas temporárias e residuais em que estamos, trata-se de nos expormos às diferenças dos gestos menores ${ }^{4}$, articulando um corpo, outrora mortificado, para poder fazer nascer um corpo vivo, animado, que atenta ao mundo. Afinal, "O corpo animado pode estar em risco e vulnerável à exposição, mas está pelo menos vivo para o mundo" (Ingold, 2020, p. 63).

Como descobrir essa forma fundamental de aprender a ser afetado e estar vivo para o mundo na continuidade da vida, no campo das relações educacionais? Ingold (2020, p. 62) afirma que essa abertura, uma percepção distraída ou animada do corpo e do mundo "[...] é a região da persistência autista, dos despertares da infância e do mundo anímico em formação", por sua vez pertencentes a um "[...] mundo de movimento e de devir, de incipiência ou nascimento contínuo, em que tudo e todos estão sempre à beira de se revelar pelo que são ou por quem são" (Ingold, 2020, p. 62).

Parece-nos se tratar de uma articulação gestual do corpo mortificado outrora soterrado pelo usual modo de pensar de rebanho, próprio das formas adulto-macho-ocidental-branco-heterossexual-inarticulado ${ }^{5}$, onde um estado provisório de ser estanca/emudece a vida que pede passagem. Uma pedagogia onde educadores são mais um emaranhado de guardiões de fins do que um catalizador de começos (Ingold, 2015b) - reduzidos a máquinas de fazer coisas, cumprir tarefas, avaliá-las, delimitálas, diagnosticá-las.

4 “[...] aquelas pequenas perturbações ou distrações onde as coisas se desviam do curso, abrindo a experiência à variação potencial” (Ingold, 2020, p. 62).

5 “Um sujeito inarticulado é alguém que sente, faz e diz sempre o mesmo, independentemente do que os outros disserem (...)” (Latour, 2008, p. 43). 
Um sujeito articulado, ao contrário, é alguém que "[...] aprende a ser afetado pelos outros - não por si próprio" (Latour, 2008, p. 43), capaz de ser movido, arrastado, efetuado por entidades diversas, componentes artificiais e naturais, "[...] cujas diferenças serão registadas de formas novas e inesperadas" (Latour, 2008, p. 43). Esse processo culmina em novas possibilidades de dizer, sentir e fazer desencadeados pelas diferenças registradas que, no entanto, não corresponderão a um mundo dado, representativo, fixado. Ao contrário, mundos se proliferam, a mais mediações se ficará sensível, diferenças se multiplicarão, mais contrastes se acrescentarão ao estado provisório de nós mesmos: estaremos cada vez mais expostos ao mundo, os inadaptados (Deligny, 2020), expostos ao espanto.

Tudo isso implica um caminho de encontrar abrigo nos processos de experimentação - ou do que Ingold chamaria de uma educação fraca ou pedagogia pobre ${ }^{6}$ - processos os quais nos solicitam paciência e prudência. Num caminhar variável e leve, a experimentação corresponde ao comungar e à variação do hábito, cultivo de uma prática atencional. Isto é: “[...] responder aos problemas do caminho, animado por novos começos do mesmo, sem entregar-se a soluções finais de cada recomeço, encontrando caminhos na medida em que se avança em resposta a variações ambientais" (Ingold, 2020, p. 68). Experimentar no hábito pode ser como um render-se aos seres e materiais seguindo as forças do que lhes acontece, expondonos ao curso do evento; talvez ler um livro sem objetivo de moralizá-lo, livre de qualquer determinação prévia exterior (objeto, sujeito, significados, interpretação, análise, etc); brincar com as palavras, usando-as como ferramentas artesanais de expressão e abertura para o mundo, "[...] libertando-as dos efeitos embrutecedores da explicação" (Ingold, 2020, p. 79); ampliar habilidades perceptivas e de coabitação (Haraway, 2021) com seres animados ou inanimados. Momentos de exposição, processo aberto de descoberta, experimentação com o real, movimento improvisador, articulações livres: gestos menores, vivos, para o mundo.

De todo modo, experimentar e habitar nessa liberdade da educação da atenção envolverá cuidado e presença. Ensejar o cultivo de um modo de se relacionar, de uma percepção ativa, de um ser que habita no hábito e cuja postura é atencional. Caímos então, num novo conceito trazido por Ingold (2020), o qual também nos é muito caro, o de cuidado, explorando uma dimensão ética da atenção, própria do que trouxemos no início desse texto: a de uma comunidade de muitos habitantes humanos e não humanos, daqueles que comungam de algo, exatamente por não ter nada em comum ou não serem compreendidos.

Cuidar de alguém ou algo deve permiti-lo estar em nossa presença para que, assim, possamos estar presentes para eles. Num outro modo de dizer: devemos deixá-los ser, para que possam falar conosco. Isso é bem importante, posto que ao contrário de reafirmarmos o que os outros devem ser considerados diante de seus contextos sociais, culturais e históricos próprios - e que, então, somente assim, o outro será compreendido e 'explicado' - a implicação do cuidado relacionado à atenção é restaurar os outros mesmos à presença ativa, “[...] para então atender e responder ao que eles têm a dizer” (Ingold, 2020, p. 49)

Nesse sentido é que cuidar não implica apenas ouvir o que os outros têm a nos dizer, mas implica responder a eles apropriadamente. E sabemos que, para responder, é preciso estarmos presentes, atentos e vivos para o que se apresenta.

Na linguagem de comunhão e variação, em que cada pessoa fala com a sua voz única e singular e não como um representante da coletividade, o que importa não são tanto as palavras que usamos, mas o fato de que devemos

\footnotetext{
6 “[...] nos induz a romper a segurança de nossas posições defensivas, tirar nossa armadura e conhecer o mundo de braços abertos. É uma prática de desarmamento. Isto é educação no sentido de ex-ducere. Trata-se de exposição e não de imunidade; torna-nos vulneráveis em vez de poderoso, mas, da mesma forma, ela valoriza a verdade e a sabedoria sobre o conhecimento. Considerando que a educação forte procura incutir o que é desejado, a educação fraca é uma busca pelo que é desejável [...] Mas acima de tudo é feita e passa pelas coisas com atenção" (Ingold, 2020, p. 58).

7 "Verdadeiramente, o que a criança quer e, na verdade, exige é atenção. Ele ou ela tem coisas a dizer, para nos dizer ou para nos mostrar e grita para ser notado. E devemos observar, ouvir e responder. Isto é o que significa cuidar” (Ingold, 2020, p. 48)
} 
responder com elas. Pois é por meio de nossas palavras, e pelas vozes com as quais pronunciamos, que nos fazemos presentes aos outros como pessoas particulares que somos (Ingold, 2020, p. 48).

Esse cuidado em educação com as crianças, por exemplo, pode se tornar um campo vivo com gestos mínimos, pelos quais falsos problemas podem ser deixados de lado pelos verdadeiros: “[...] estes são problemas que não cedem a respostas, mas apenas a problemas futuros, novos encontros, novas aberturas” (Ingold, 2020, p. 72): algo tão vivo quando se está na convivência com crianças, esses “[...] entes pulsantes, visíveis, existíveis, criadoras, dançarinas na arte de desvelar mundos alegres, dimensões e planos ainda inexplorados do pensar e do sentir [...]” (Dalmaso, 2020). Nesse tom, se são corpos em vias de serem afectados junto de nós, podemos todos juntos angariar processos de renovação, presentes no aqui e agora, trazidos à nossa atenção. Animados, "Eles agem, eles falam diretamente para nós, nos fazem pensar: não apenas sobre eles, mas com eles. Eles se tornam parte do nosso mundo, como nós somos parte do mundo deles. Nós nos importamos com eles, como eles se importam conosco" (Ingold, 2020, p. 75).

Nesse caminho, estaremos expostos a também sermos educados pelo mundo - pessoas de diferentes idades, seres de todas as formas e conteúdos, materiais, encontros multifacetados - ao que nasce continuamente diante de nós. Atentar ao que as pessoas fazem, ao que nossos gestos provocam em nós e no mundo, às histórias que podem ser lembradas e narradas, para quem sabe imaginar futuros. Novamente, isso envolve exposição e espera: "É como empurrar o barco para um mundo ainda não formado - um mundo em que as coisas não estão prontas, mas sempre incipientes, à beira do surgimento contínuo" (Ingold, 2020, p. 91).

Parece-nos que se trata de seguir promovendo aspirações, de um processo de vida vivido em companhia de outros em sua alteridade constitutiva, para a construção do que chamamos de vida social: é o que determina o princípio do hábito, onde a humanidade é uma conquista relacional sempre em curso. Que aspectos podem ser angariados, em relações e nas instituições sabidamente conhecidas em nossa sociedade ocidental?

Professor e aluno, então, longe de estarem frente a frente como respectivamente instruídos e ignorantes, seguem na mesma direção, como pessoas, cada uma com uma história particular para contar, atendendo e respondendo um ao outro ao longo de uma jornada que eles empreendem juntos; mas em direção a que resultado, ninguém sabe (Ingold, 2020, p. 57).

Acoplamento participativo, correspondência de hábitos, agenciamento. Para que a vida continue assim, o convite é criar um ambiente onde você, educador/a, ofereça tudo que tem de si para experimentar, até não sobrar nada, até fracassar em tudo que se tem e que se é, liberando as armas de combates outrora conquistadas, para "[...] responder um ao outro com espírito de responsabilidade e cuidado" (Ingold, 2020, p. 115).

Como escreve Deligny precisamos nos afastar da vontade de verdade de um método pedagógico para tal, ao contrário, é preciso que invistamos em “[...] ajudá-los a viver” (Deligny, 2018, p. 151), a partir de movimentos alegres, leves e provocadores. É preciso cultivar em nós, seres que habitam os contextos da educação, uma vontade vívida de viver aterrados no real da vida que se experiencia, de percebê-la, de senti-la. É crucial que sejamos capazes de recriar o mundo nas ações que mobilizamos, o que vem ao encontro de esquivar-se de um consumo exacerbado das ideias e conteúdos transmitidos e passíveis de transmissibilidade, potencializando aspectos atencionais que reconhecem nossa presença e subjetividade agenciados a fatores eco e etológicos (Guattari, 1992), apostando na proliferação do estar vivo e tudo aquilo que emerge na medida em que nos percebemos habitando o próprio fluxo da vida, do pensar e do sentir.

\section{Considerações Finais}

Nas maiores confusões, você é a calma sorridente. Nas grandes calmarias, você é o vento (Deligny, 2020, p. 29). 
De quantos conceitos, pontes, linhas e emaranhados se fazem necessários para produzir novas paisagens educacionais, novas potências relacionais? O que tentamos trazer neste manuscrito foi a invenção dessa paisagem, um tanto mista e confusa, nebulosa e virtual, porque múltipla e complexa, aberta às intercessões que o próprio leitor necessita lançar mão.

Nos termos conceituais que trouxemos, o que pode a educação? Uma prática de cuidado e presença, uma maneira de 'fazer passando por algo', na liberdade experimental do hábito, comungando socialmente da experiência, em sua ordem da variação e mudança, instaurando, cada vez mais, um corpo capaz de ser afectado-movido-animado, e "[...] restaurando a memória e a imaginação para o alongamento temporal da vida" (Ingold, 2020, p. 72). Uma prática da atenção implicaria na abordagem dessa educação ecológica (Ingold, 2020), a qual corresponde a uma certa habilidade corporal entre ação e percepção do humano no mundo, vivendo em meio às coisas e seres.

Como pesquisadoras em universidades, estabelecemos um convite aos educadores em suas relações, podendo disseminar este imbricado modo atencional trazido neste texto. Educadores de toda ordem, pais, novos, velhos, crianças, jovens de todo contexto e especificidade, unem-se em uma comunidade desarmônica de iguais, "[...] mas uma comunidade onde cada um é diferente, e cada um tem algo para dar" (Ingold, 2020, p. 71). Suspendem-se destinos, autarquias, armadilhas sociais de cumprimento de uma identidade, "[...] a perfeição de métodos de ensino, a simplificação de argumentos complexos, a explicação de explicações [...]" (Ingold, 2020, p. 77), desintensificando o embrutecimento, expondo o corpo a articulaçõesafetações à nossa diferença molecular, liberando-as e trazendo-as para "[...] a presença no aqui e agora, e colocando-os à disposição de todos" (Ingold, 2020, p. 71). Trata-se, sempre, de algum modo, de aprender.

Aprender a estar vivo é aprender. Por isso parece-nos tão consistente pensar em estar atento ao que o mundo nos convoca, assumindo o risco de um viver que afirma o que chega, somando forças e abrindo espaço para o que sentimos, nas dobras. Estar conectado com os chamados, nas existências impensáveis, porém, que por direito, nos ajudam a investir em modos não ideias nem romantizados de sofrer e se alegrar, de amar e cuidar, morrer e de viver, de estarmos juntos em educação (Rigue; Dalmaso, 2020, p. 146).

Arregimentar gestos menores, fazer poesia juntos, para desencarcerar os mundos demasiadamente sentenciados da explicação compulsória, “[...] da quantidade demente de falas e imagens" (Deleuze, 2013) e do embotamento, os quais, sobremaneira, dominam nossas práticas, gestos e habitações no que denominamos de educação escolarizada. Estaremos sempre falando de processos educacionais que, para além do bem e do mal, envolvem toda ordem de modificações-movimentações sobre si mesmo em afetação recíproca com o mundo.

Interessa-nos, assim, pensar nos atravessamentos da atenção enquanto conceito que movimenta uma nova produção de campo estratégico, ao compor com espaços, práticas, discursos, políticas, ações, gestos, problematizações, sejam quais forem as funções que desempenhamos, nos lugares que ocuparmos. Alguns possíveis, talvez, nasçam disso: para que esse contexto atencional dê novos futuros pelos espaços educativos que ocupamos e produzimos, é latente um sonhar a instituição, espaços, invenções criativas de pensamento e processos formativos (Krenak, 2020). E uma instituição, relação e formação que admite o próprio sonho é aquela que abre campo para que sonhadores habitem esse lugar, "Onde as pessoas aprendem diferentes linguagens, se apropriam de recursos para dar conta de si e do seu entorno" (Krenak, 2020, p. 34).

Ficar naquilo que surge, expandir as peles de que somos vestidos para deixar que tudo possa chegar em nosso corpo indeterminado, na comunicação entre fluxos sociais, biológicos, linguísticos, políticos, emocionais. Investir e abrir frestas de sonhos-corpos-afetos da atenção: um engajamento alegre e exposto ao que se foi, ao que se está sendo, e ao que ainda está por vir em educação. 
Research, Society and Development, v. 10, n. 14, e117101421831, 2021

(CC BY 4.0) | ISSN 2525-3409 | DOI: http://dx.doi.org/10.33448/rsd-v10i14.21831

\section{Referências}

Coccia, E. (2020). Metamorfoses. Dantes Editora.

Corrêa, G. C. (2014). EJA, educação e escolarização. Anais da X ANPEDSUL, xanpedsul.faed.udesc.br.

Dalmaso, A. C. (2016). Fiandografia: experimentações entre leitura e escrita numa pesquisa em educação. (Tese de Doutorado, Universidade Federal de Santa Maria, Santa Maria, Brasil). https://repositorio.ufsm.br/handle/1/3503.

Dalmaso, A. C. (2020). Quando o sol é tão forte como um mel: experimentações de existir - escrever, pensar, comunicar - com crianças. Revista ClimaCom Devir Criança. 7(18). http://climacom.mudancasclimaticas.net.br/quando-o-sol-e-tao-forte-como-um-mel-experimentacoes-de-existir-escrever-pensarcomunicar-com-criancas-alice-copetti-dalmaso.

Dalmaso, A. C.; Rigue, F. M. (2020). O convite da Atenção e seus efeitos em Educação: entre labirintos, feitiçarias e cuidados. In: Neuscharank, A.; Halberstadt, I. A.; Zanatta, J. M. Z. (Orgs.). Possibilidades... Aprendizagens, experiências e gestão na educação. Beau Bassin: Novas Edições Acadêmicas, p. $19-40$.

Deleuze, G. (2002). Espinosa: filosofia prática. Escuta.

Deleuze, G. (2013). Conversações. Editora 34.

Deligny, F. (2018). Os vagabundos eficazes - operários, artistas, revolucionários: educadores. n-1 edições.

Deligny, F. (2020). Semente de crápula. Conselhos aos educadores que gostariam de cultivá-la. n-1 edições.

Guattari, F. (1992). Caosmose: um novo paradigma estético. Editora 34.

Haraway, D. (2021). O manifesto das espécies companheiras: cachorros, pessoas e alteridade significativa. Bazar do tempo.

Ingold, T. (2010). Da transmissão de representações à educação da atenção. Educação, 33(1), 6-25, https://revistaseletronicas.pucrs.br/ojs/i ndex.php/faced/article/view/6777.

Ingold, T. (2015a). Estar vivo: ensaios sobre movimento, conhecimento e descrição. Vozes.

Ingold, T. (2015b). O dédalo e o labirinto: caminhar, imaginar e educar a atenção. Horizontes Antropológicos, 21(44), 21-36. http://dx.doi.org/10.1590/S010471832015000200002 .

Ingold, T. (2020). Antropologia e/como educação. Tradução de: Vitor Emanuel Santos Lima, Leonardo Tangel dos Reis. Vozes.

Lapoujade, D. (2017). William James, a construção da experiência.

Latour, B. (2008). Como falar do corpo? A dimensão normativa dos estudos sobre a ciência. In: Nunes, J. A.; Roque, R. (Orgs). Objectos impuros. Experiências em estudos sociais da ciência. Edições Afrontamento.

Krenak, A. (2020). A vida não é útil. Companhia das Letras.

Krenak, A. (2019). Ideias para adiar o fim do mundo. Companhia das Letras.

Rigue, F. M.; Dalmaso, A. C. (2020). Estar vivo: Aprender. Revista Criar Educação, 9, 130-147. http://periodicos.unesc.net/criaredu/article/view/6354. 